\title{
Destructive Groups: The Role of Projective Identification in Suicidal Groups of Young People
}

\section{Goldblatt1, S. Briggs2, R.Lindner3}

\begin{abstract}
:
Group suicidal behaviour by young people has been attracting increasing worldwide attention, but the subject has rarely been studied from a clinical or psychodynamic perspective. Although etiological factors are not well understood, unconscious as well as conscious group processes likely contribute to self-destructive actions. (Sentence deleted here). In this article we discuss the role of projective identification in the development of suicidal behavior by individuals who are part of a destructive group. We consider how these factors may operate, illustrated through a case description of a young man involved with a group of high school students that included at least four who made serious suicide attempts. Recognition and understanding of these forms of communication have important implications for clinical practice and suicide prevention.
\end{abstract}

1 Harvard Medical School, Harvard University, MA, USA

2 Professor of Social Work, University of East London, UK

3 Hamburg -Eppendorf University, Germany 
Key words: projective identification, suicide groups, adolescent suicide, group dynamics, point cluster

\section{Introduction}

Group suicidal behaviour amongst young people has received increasing worldwide attention following the recent spates of suicides in South Wales (Jones et al, 2013) and South Australia (Austin, et al, 2011). Considerable uncertainty remains about the mechanisms through which suicide and suicide attempts spread through groups of young people (Haw et al 2013). There is increasing attention to the role of Internet social media, which may contribute to an increase in this phenomenon (Austin, et al, 2011). Very little attention has been paid to group suicidal activity from a clinical perspective, though its presence undoubtedly creates an anxiety provoking set of conditions for the psychotherapist, and generates challenging questions technically, practically and ethically. In this article we explore the experiences of working in individual psychotherapy where it becomes evident, over time, that the teenage patient was one of four young people in his friendship group who were involved in suicidal behaviour. We describe this therapeutic experience and discuss the role of projective identification in group dynamics as observed in individual psychotherapy. As group suicidal behaviour has not been discussed in the 
psychoanalytic literature, we also briefly survey what is known, epidemiologically and sociologically, about such group behaviour.

Group suicidal behaviour is usually discussed using the term 'cluster'. The occurrence of an unusually high number of suicides in a small geographical area or institution, over a relatively brief period of time, is referred to as a point cluster ((Haw et. al. 2013). Such clusters are thought to be rare but may occur more commonly amongst adolescents, affecting $1-5 \%$ of teenage/young adult suicides (Zenere, 2009). The connection between individuals in these clusters is not limited to close friendship groups, but may involve individuals who "share some connection, however fragile or self-perceived; they typically have not planned their deaths together" (Zenere, 2009, p.14). A point cluster is not synonymous with a 'suicide pact', which is a consciously made, joint decision by participants to die by their own hands. Suicide pacts are also thought to be relatively uncommon in adolescence (Zenere, 2009).

Point clusters are differentiated in this terminology from 'mass clusters', which are typically suicides in response to an event reported in the mass media, such as the suicide as a celebrity. In mass clusters the increase in suicides occurs at a similar time, but in different places, and could now include group suicidal behaviour through social media. Since the publication of Goethe's (1774) “The 
Sorrows of Young Werther" 4 it has been assumed that these 'copycat' suicides were due to contagion. The notion of contagion implies that something is transmitted, just as in the case of infectious diseases, between people without a strong apparent sentient connection with each other. However, contagion is only one of a number of potential explanations for how suicidal behaviour spreads in groups. The mechanisms of communication and influence remain unclear (Boyce, 2011). In a systematic review of the literature, Haw et al (2013) identified various psychological mechanisms that may account for the transmission of suicidality in point clusters. These include modelling (Bandura, 1977), priming (Berkowitz, 1984), imitation (Durkheim, 1897/1951), complicated bereavement (Johansson, Lindqvist, \& Eriksson, 2006), homophily (Joiner, 1999), and assortative relating/susceptibility (Chotai, 2005). Identification with the suicide victim, a variation of Anna Freud's (1936) notion of identification with the aggressor as an ego defense, has been considered as a mechanism of communication between suicidal inpatients with psychotic illnesses (Sachs \& Eth, 1981) and in 'copycat' suicides (Austin et al, 2011). Projective identification has also been suggested as an intrapsychic mechanism of suicide contagion (Tainminen, 1992), but this has not been further developed with regard to suicidal groups, though Shapiro (2009) discusses its application to groups more generally.

4 Goethe's novel generated a fashion across Europe for imitating the eponymous hero, adopting his suicidal solution to the impossible realisation of his love for a woman who was betrothed to another man. 
In this paper we explore how the application of projective identification to destructive groups can offer a framework for understanding the communication of violent self-destructive processes between individuals in a suicide point cluster. As the term 'cluster' has a precise meaning and usually indicates a statistically significant increase in suicides at a given time and place, we will restrict ourselves to using the term 'group' in this article. Our focus is a friendship group of high school students. In other cases, including, for example, those widely reported as happening in South Wales, clear friendship ties between suicidal teenagers are sometimes not necessarily evident.

\section{Projective Identification and Destructive Group Dynamics}

In this paper we take up Tainminen's (1992) suggestion that projective identification is a key factor in suicidal group dynamics. The concept of projective identification has been discussed in what is now a huge literature, with emphasis on both clinical and social applications. In clinical settings, there are many applications of projective identification; it has been described as "a form of adaptation, communication, defense, and creative expression that permeates the core of many psychotherapeutic treatments" (Waska, 1999, p.156). Melanie Klein's (1946), original formulation of projective identification was that it formed the basis of an aggressive object relation, an omnipotent 
phantasy in which (unwanted) aspects of the self are disowned and projected into another (originally the interior of the mother's body) as a primitive defense mechanism, in order to control her from within. Bion (1962) subsequently redefined and expanded the concept to include a more benign notion of projective identification as a communicative process; emotional experiences (in particular anxieties) that are felt to be too powerful to be internally managed are communicated to a (receptive) other, in an attempt to get responses that assist in understanding emotional experience and achieve self-regulation. Although similar and overlapping, these two formulations of projective identification contain important distinctions. In Klein's original formulation it is used with aggression and aims to obliterate the object, while for Bion the purpose is communication. At times, there may be a fine line between these two concepts; the more intense evacuative aspects of projective identification are usually considered as excessive, damaging to thinking and relatedness, and accompanied by a violent splitting of the object; while the more aggressive impulses behind projective identification can be thought of as communication of feelings that cannot be thought about. This aspect of Bion's extension of Klein's concept is particularly relevant to considering projective identification in suicidal individuals and groups, where anxieties can be particularly intense (Chabrol \& Stzulman, 1997).

Projective identification has been widely studied for its operation in 
social, organisational and therapeutic groups (e.g. Main, 1975; Young, 1992; Halton, 1994; Armstrong, 2005). Of particular relevance to this paper is the role of projective identification in adolescent groups, and thus in the process of adolescent development. In adolescence, the experience of growth and change involves fluctuating states of mind and diverse ways of relating to others. Adults commonly may be used as temporary recipients of projections, enabling containment of anxieties (Anderson, 1999, p.166). Peer groups play a significant role in aiding the process of separation and individuation, and as with all groups, "the psychic price of admission is to enter into that group's splits and projective identifications" (Young, 1992).. Of course it is well known that intense friendship groups in adolescence and, indeed, throughout the life cycle, are likely to be characterised by projective identification. In adolescence, identifications with other group members are demonstrated through ordinary social behaviour, for example, by wearing similar clothes and following the same trends in music. Identifications may develop within the group such that "various individuals represent different aspects of each-others' personalities, ones that are desired or repudiated" (Waddell, 1998, p. 135). Projective processes in adolescent groups range in intensity and effect. They may be benign and helpful, for example, fostering the capacity to trust outside the family; or malevolent and destructive, where gang-like characteristics can "sanction the expression of destructive feelings and attitudes" (Waddell, $1998 \mathrm{p}$. 137). Waddell, emphasizes the flexibility of most adolescent groups, their 
capacity to move between more and less benign modes of relating, and refers to these oscillations as "groupings or gangings-up".

Though there are a number of ways of conceptualising group dynamics, the contrast between group and gang may be useful in distinguishing ways of relating in destructive peer groups, as the more destructive kind of projective identification is associated, in this view, with gang dynamics. The difference between group and gang dynamics (Waddell \& Williams, 1991; Williams, 1997) are that in 'gang dynamics', the aim is to do damage (to parental objects) under the guise of protecting members through adherence to the powerful leader (represented as the 'Godfather' or cruel superego). This aim, of doing damage to the parental object accords with the view, expressed by many writers, notably Laufer (1985) that in adolescent suicidal behaviour, an attack on the parent (internal and external) takes place. In 'group dynamics', in contrast, members may hurt each other through competition or exclusion, but an underlying consideration towards group members remains present (if not always available), and the group does not primarily exist to hurt others (Williams, 1997).

The development of either kind of association likely reflects the transitory needs of adolescent development. More consistent membership of a particular kind of 'grouping' or 'ganging-up' may also reflect an emerging high valency for "instantaneous involuntary combination of one individual with another for sharing and acting on a basic assumption" (Bion, 1961 p. 153) through the 
collective use of projective identification. Bion's idea of valency provides a way of conceptualizing "how collusive, shared group phenomena such as scapegoating, and emotional contagion are rooted in the collective use of projective identification" (Clarke, 2001). In adolescence, individuals with a shared, high valency for self-destructive solutions to the pains of separation and growth, and a propensity to feel hurt and misunderstood in relationships with significant others, can get to share a fantasy of resolving the problem through violent projective action. For example, in an inpatient unit, a group, or, rather, 'ganging-up' of adolescents was observed getting into a frenzied competitive state about the extent to which their parents would feel remorseful after their suicides (Author, 2008a). Projective identification is, therefore, an important, multi-faceted concept with relevance for adolescent suicidal groups. To explore how these processes might operate in these groups, we present a case discussion of a young person treated in psychotherapy, after a suicide attempt and whose peer group was involved in suicidal behavior. We first present a detailed account of the case, and then we assess how it relates to this theoretical discussion.

\section{Case report:}


Sven $^{5}$ was an 18 year old male who made a serious suicide attempt shortly after the start of his final year in high school while he was interviewing for university at his old hometown. Following initial stabilization he was treated in intensive outpatient psychoanalytic therapy that lasted for 9 months before he terminated and went off to college. During this time at least three other young people in his immediate cohort at school were involved in suicidal behaviour and this discussion will include references to suicide attempts by two of these peers.

\section{Personal History:}

Sven says he was a happy child, involved in sports and schoolwork and had a good relationship with his siblings and friends. His parents divorced when he was 5 years old, and his father left their hometown. He appeared to have adjusted to this loss. However, when he was 15 years old his mother began a romantic relationship and decided to move out of state to be with her new husband. Sven was enraged and protested at first, but when he was unable to have any effect on mother's decisions he felt helpless and vowed: "I'll do anything not to move, I'd rather kill myself'. He moved to their new home in a chronic state of rage, and thought constantly of how and when to kill himself.

${ }_{5}$ All names and identifiers have been changed to preserve confidentiality. 
Over the course of the next three years in his new high school Sven made little effort in his schoolwork, and formed just a few superficial friendships, mostly based on being in classes together. His social life was quite restricted, and he spent most of his time playing games on the Internet. One of his friendships was with Eric, a charismatic youth who was involved in a turbulent relationship with Kamina, a girl in their class. Sven would ride the train each day to school with Kamina, and he heard about her relationships. He felt they were getting close.

Soon after the start of his senior year in high school Sven and his classmates went on a school weekend camping trip. During this time there was some distress involving Eric and Kamina. The next week, Sven travelled with his mother to interview for university placement, for the following year. Sven felt the interview went well. He decided that night to kill himself. He overdosed on pills that he carried with him for that purpose. The next morning his mother had difficulty waking him and took him to the Emergency Room which resulted in his being hospitalized.

During the hospitalization it was discovered that Eric had revealed to Sven his own plan to kill himself. On the day that Sven was leaving town for the college interview, Eric told Sven that he had just overdosed. Although he knew of Eric's serious suicide attempt, Sven decided not to tell anyone about Eric's dire situation. He turned off his own cell phone and left town. He decided 
at that point to end his own life. He truly intended to die, and regretted surviving, saying, "I suppose it doesn't matter much". Sven appeared indifferent when he was later told that Eric had survived his suicide attempt.

Following their suicide attempts, Sven and Eric were each separately offered individual psychotherapy. The school was actively involved in monitoring their compliance with treatment but no counselling or clinical input was offered from within the school. The setting was thus one in which there was an emphasis on individual treatment with no overall coordination. Although Sven and Eric's suicidal behaviour was known to the school, very little was known about the involvement of other students in this process. The gradual emerging of information and unfolding relationships was a feature of the difficulties faced in managing these situations. These issues are addressed in a separate paper.

\section{Psychotherapy}

Treatment focused on Sven's internal experience of feeling socially isolated and withdrawn. He said he tried to be neutral, to avoid affective experiences, in order to diminish his feelings of hurt, shame and rage; affects which were initially stirred up by his mother's decision to remarry and move their home. Sometimes the isolation of affect worsened to a feeling of depersonalization or 
dissociation. Sven's goal was to get through his final year of high school and return to his old hometown for university where he could live a fantasy life free of outside disturbance. However, he made no efforts with his schoolwork and fell further and further behind, thereby jeopardizing his graduation and entry into university.

Faced with his neutrality and indifference, I tried to take an active stance, in order to help explore his inner experience of home, school, mother, and friendships. An active stance has been shown to be an effective approach when working with suicidal patients (Author 2008b; Weinberg et al., 2010). However, here it caused Sven to dig in his heels and left me feeling frustrated and confused. He experienced me as intolerably intrusive and became even more withdrawn and fell further behind at school. It was possible to surmise that Sven was projectively inviting an active approach - which he could then reject. Even after I realised what my active stance was causing, I still found myself pulled into it, despite my conscious awareness that I did not want to be actively asking about homework or school performance. I was thus being "manipulated so as to be playing a part, no matter how difficult to recognise in someone else's phantasy" (Bion 1961, p.149). When I was finally able to tolerate his indifference and potential failures and his projections of confusion and frustration, I found he became more able to tell me about his internal experiences. He was able to acknowledge that his indifference was a way of trying to control overwhelming feelings of rage, shame and hurt. 
At about 3 months into treatment, as the Christmas vacation drew near, it appeared that Sven had become somewhat more involved with his classmates and seemed to be quite popular, despite his avowed indifference. In psychotherapy he began to discuss the events that led up to his suicide attempt at the end of the summer. He revealed that although Kamina was Eric's girlfriend, Sven felt that he had gotten close to her and in fact, they had begun a sexual relationship. Sven felt unbearably guilty because Kamina ended her relationship with Eric over the weekend of the school camping trip. He couldn't understand why Eric confided in him and treated him like he was his best friend. Twenty-four hours later Eric overdosed, and 24 hours after that came Sven's own suicide attempt.

He perceived my counter-transference concern for his commitment to schoolwork as acting like his overly intrusive mother. Sven needed his space, and would do almost anything to get it. As I became less questioning and more empathic, Sven also revealed that he had formulated suicide as a way to get some distance from a mother whom he perceived as overly involved, and from whom he could not have his own space to think, feel or have fantasies. Later in the therapy, when he was more able to share his thinking, he told me about how he set rules for himself and others: "Two rules I try and hold myself to. (1) Don't spread information that you don't want spread. (2) Don't Lie. I really dislike lying. I've found clever ways to avoid the truth. I don't lie except to 
preserve rule number one". An important consequence was: “if you can't follow Sven's rules then you get silence. If you get too close you're going to find yourself far away". This ideology of keeping unwanted feelings and relatedness at bay was a key feature in his therapy, projecting powerfully into me all responsibilities for emotional contact, intimacy and shared understandings.

As the Christmas vacation approached, I recognised the difficulties of the upcoming separation and suggested several ways to remain in contact over the break. Again, Sven rejected my active interventions. After the break he did not want to return to therapy. Fortunately, school insisted that he remain in treatment in order to continue attending classes and graduate. So, he returned for regular psychotherapy, even though mother felt he should be decreasing his visits, and move on to other interests. Once again, Mother felt overly intrusive and antagonistic to treatment. On his return to therapy Sven's symptoms of withdrawal and dissociation were worse. He was not actively suicidal, but appeared distant, monosyllabic and he felt hopeless about change.

As regular sessions followed, Sven's mood and functioning gradually improved. At about 5 months into treatment Sven spontaneously raised the issue of suicidal behaviour amongst his peers. He described an incident at school where noticed that Eric's phone indicated "message waiting". Eric had tossed it down and would not look at it until after school. Sven thought it might be from 
Trish, a girl in their group who had been looking distressed. Sven picked up the phone, listened to the message, and discovered that in fact it was from Trish. She was in the midst of a suicidal crisis. She was home alone, taking a deadly amount of medications. Sven jumped into action. He rallied his group of friends to inform a teacher, call Trish's parents and jump in his car to drive out to her house about an hour away. They arrived to find Trish passed out. Sven called the ambulance and her parents. He comforted another girl in the group who was having a hard time dealing with this suicide attempt. The next day, in his therapy session, Sven acknowledged the difference between his reaction this time and following Eric's suicide attempt in the summer.

Session Transcript:

Sven: It's a pretty drastic change, and I don't even know Trish that well.

Therapist: What's different for you?

Sven: I'm not suicidal anymore. It's a different mindset. Trish's reasons for suicide were stupid. She thought all her friends hated her, which is not true. She was basing her decision on faulty logic.

Therapist: You could recognize that.

Sven: Yeah

Therapist: What's different about the suicidal and non-suicidal mindset? 
Sven: If I'm going through life assuming I'll end my life soon, then I don't care to put any effort into anything. I don't care about anything. Sure, it will cause stress, but there's no reason to avoid that. Whereas if I'm not planning to end my life, there's no reason for her to go through with that. She's decent. If I'm thinking it's not a bad choice for me, then it's not a bad choice for her. With Eric - I just wanted to respect his decision. This time though, I felt pretty good because I handled things really well. Her parents thanked me. I handled it in a mature way. I spoke with Trish's parents and Eric's parents and that felt mature.

Therapist: Where did this maturity come from?

Sven: Hard to say. I was thinking why is this different? If I were to talk with you it would be strange to tell you that I had acted the same as I did with Eric. That I turned off my phone and pretended I didn't care. It's not that you would think this is what I should or shouldn't do. It's how I would I tell you about it? How would that conversation go?

This session marked a point of therapeutic change, acknowledged by both patient and therapist. I was aware that something has changed, but was unclear what. By my questions I hoped to clarify Sven's state of mind and his perceptions. I found it reassuring (and probably, so did he) that he was no longer suicidal and that something had changed in his thinking process. As Sven describes the switch between the suicidal and non-suicidal mindset, I felt a relief associated with the lifting of a huge weight (the unspoken suicidal threat) 
that Sven has lived with for so long, and which I too had come to bear. Sven seemed to imply that at the time of Eric's suicide attempt, he and Eric shared a morbid sense of destructiveness, passed between each other. Unlike his switching off from Eric's problems, with Trish's suicide attempt Sven was mobilised to help her with her 'bad feelings' and not to try to escape from them. Of course the dynamic between Sven and Trish was very different from his relationship with Eric, with whom he was rivalrous over Kamina. My sense of relief (where did this maturity come from?) is reflected in Sven's answer, that basically he is now aware (even consciously) that there is a significant other in his world, who is involved in the process of managing his inner life.

I felt transiently relieved, but I found I was fearful of further destructive projections. The fragility of the change appears in the tentative way Sven acknowledges the importance of the therapeutic alliance. When he says, "If I were to talk with you it would be strange to tell you that I had acted the same as I did with Eric, that I turned off the phone and pretended I didn't care", he is able to recognise, with some hesitancy, and a certain distancing ('it would be strange') his awareness of a truthfulness in the therapeutic relationship and an internalisation of the importance of the relationship, in which he is separate from and not invasively fused with his therapist, as occurred in the maternal transference. 
At the same time, I was becoming more aware of the other dangerous players in Sven's world, and their effects on me. Countertransference fears for the safety of Trish, Eric, Kamina and possibly others made me want to take action to ensure their safety. However, along with this anxiety came a sense of helplessness and confusion; I felt torn between therapeutic confidentiality and a felt responsibility for the members of Sven's friendship group. My sense of confusion and helplessness is in marked contrast to the clarity with which Sven describes his 'mindset'. It may be, on reflection, that in addition to the complex external situation, the feelings of confusion are projected into me by Sven to allow him relief from the contradictions in his position, and the threat that a therapeutic relationship presented to his 'rules' through opening up levels of meaning and shades of grey in relationships, and the accompanying emotions. I imagine that after many years of hostility and rage against parental figures, to find a different relationship with someone, with whom he possibly wished to identify, might be experienced as confusing. It seemed, therefore, that I needed to be watchful about the feeling of relief from suicidal anxiety and whether destructive behaviour would resurface in other members of the group. In that moment I felt the relief from suicidal anxiety to be encouraging; subsequently in the therapy, and on reflection, the anxiety for other group members and my confusion became equally important factors. 
In fact, as the school year ended Sven was determined to leave after graduation. He kept re-assuring himself, "I should be fine". He said he was no longer seriously suicidal: "It went away because I allowed myself to become part of the group and consider them friends, as opposed to just people that I hang out with. That's different." Though he had made changes and was clearly not himself actively suicidal he maintained 'Sven's rules' and I had the sense of being quite ruthlessly pushed away, perhaps as a consequence of having got too close and stirred up his longings for closeness and being able to rely on someone else.

\section{Discussion:}

This case demonstrates some of the complex dynamics in working with a young man who for some years had suicidal thoughts and who made a serious suicide attempt. Within the therapy there is a continuous struggle to engage with the emotional and relational experiences that led to his suicidality, complicated by extensive suicidal behaviour in his peer group. Over time, a way of relating to Sven was found in his therapy so that he was able to make use of the therapy and also reveal and discuss a great deal about his ways of thinking about suicide. In this discussion we now focus on the role of projective identification in these

processes, linking the theoretical position outlined earlier with what we have learnt from the clinical work. 
It has often been noted that suicide can be understood as interpersonal, or dyadic; someone is -often unconsciously- hurting someone else (Bell, 2008). In adolescent suicide the interpersonal attack is simultaneously an attack on the self and the parental object (Laufer, 1985). Sven's suicidality is at one point described as an attack on his mother, whom he felt to be intrusive, taking for herself ownership of his achievements. He reached a suicidal solution to the problem of his mother ignoring his pleas not to remarry and move home, which he also experienced as extremely intrusive into his own life. This became an ideology - Sven's rules - which had the impact of powerfully projecting the responsibility for intimacy, emotional contact and safety into his therapist. The therapist was thus initially 'nudged' (Joseph, 1989) by Sven's projective identification into an active role, but as he became more aware of Sven's destructive projections, and was able to tolerate Sven's indifference to potential failures, and threats of premature termination, he was more able to recognise and tolerate Sven's unwanted feelings that were projected into him, enabling Sven to overcome his own hostility and aggression, which he had turned on himself. This appeared to have a somewhat lasting effect, as his suicidality did not return. However, this therapeutic process was both informed and complicated by the suicidal behaviour in the peer group, and this leads to an alternative assessment of Sven's increased maturity and movement away from suicidal feelings. 


\section{Projective identification in the friendship group}

The assessment of dynamics in Sven's friendship group is necessarily partial and therefore involves an element of speculation, as the source of information is limited to Sven's account. The material about his peers can be understood as communications - including aspects probably projectively located in his friends - about Sven's internal relatedness as well as about the external social relations and the interplay of projections in the group.

As it has been widely recognised that projective identification plays an important role in intense friendship groups, we start by proposing that this group will follow this general tenet. The important issue, then, is to explore characteristics of projective identification in this suicidal group, and how these lead to or promote suicidal behaviour. We suggest that this group of social peers influenced each other through their shared and projected disappointment and rage at family caretakers. We have strong evidence this is the case with Sven himself and this fits with the view that susceptible youngsters, particularly those with impaired ego strengths, may turn their rage at inadequate caretaking in the present, on themselves or others in their immediate group, through projective identification (Shapiro, 2009). From this viewpoint, we can approach understanding the role of projective identification in this group through two aspects of the material available from Sven's psychotherapy; these are, firstly, 
how the therapist's counter-transference informs understanding, and, secondly, the patterns of relatedness identified in the group, based on Sven's accounts.

Aspects of the counter transference have been discussed in the case report and above with the focus on Sven's individual psychotherapy. As the awareness of the suicidal group developed in the course of therapy, experiences of anxiety about destructive projections, relief, confusion and helplessness were important. When Sven generated relief in the therapist - that he was not suicidal -and, subsequently, confusion and helplessness - that other members of the group may be at suicidal risk, these provided indications of the quality of projective processes operating in the group. These ideas, which arise partly through reflection on the case material and thus could not be tested at the time, can now be thought of in relation to the knowledge of the group dynamics gained through Sven's accounts.

We gain some access to understanding the processes in the groups through identifying, from the history of the friendship group as described by Sven, two distinct ways of relating, which map to the earlier discussion of group and gang dynamics. In the first of these patterns, which has points of contact with a gang dynamic, or 'ganging up', associations between individuals are motivated by 'hanging out' rather than true friendship and there appear to be reduced morality or codes of conduct to guide the participants. Thus Sven does not pick up the phone when Eric is suicidal, he complains about Eric's wish for 
a more intimate 'best friend' relationship with him, and there is no ethical regard for others' relationships; Sven and Kamina get sexually involved whilst she is Eric's girlfriend. In this mode of relatedness the group is the receptacle for projections and narcissistic needs, and has all the characteristics of the paranoid-schizoid position (Klein, 1946) including greed, cruelty (by omission and commission) as well as self-destructive thoughts and impulses that are passed projectively from one to another of the group members. They have high valency for combining with other group members who share their lack of concern for the wellbeing of anyone else, summed up by the idea Sven elaborates of a 'suicidal mindset', in which it is stated that if suicide is good enough for one, it is good enough for all; a dictum emanating therefore from a particularly cruel superego.

This is further underscored by Sven's self-organization (i.e. his rules of life stress that you don't reveal too much about yourself, and try not to lie, except to protect yourself). This narcissistic mode of relating appears to have a family resemblance to the notion of 'ganging up' discussed earlier, which can be applied here to provide a way of thinking about the possible ways of functioning in the group. The ganging-up functioning of this group accords with 'gang mentality' in which there is "the evasion of feelings of guilt, by projecting all responsibility for exercising ethical judgment" (Meltzer, 1984, p. 166). That this responsibility is projected by Sven into the therapist indicates this is split- 
off, projected and located outside the group and suicidal behaviour expresses the hostility to and disappointment of parental figures, which is consistent with other formulations of the meaning of suicidal behaviour as an attack on the parental object (Laufer 1985).

The second mode of operation in the group appears quite different: friendship matters, and individuals rally to the needs of others, as illustrated by Sven's actions to save Trish. Recognition of responsibility for the effects of one's behaviour on others can lead to a sense of guilt. For example Sven felt unbearably guilty that Kamina had ended her relationship with Eric. The possibility of ethical action and individuality is restored. However, when the associated emotions are overwhelming, there can be a tendency to act projectively in order to rid oneself of these feelings. When projective identifications are contained within a relationship, there follows greater capacity to manage feelings by thinking within relationships rather than by projective action. In this second mode of group relatedness, as illustrated by Sven's material, there is a better connection with adults; Sven has an internalised sense in his mind of how he could talk to his therapist about Trish's suicide attempt, for example. The flexibility of this group (Waddell, 1998) between the two modes of operation suggests the vulnerability of the members to the destructive projections when their own defenses are regressed or compromised, and when there is limited containment of their emotional experiences. 
However, this does not take into account some of the clinical data. The above discussion appears to characterise Sven's different modes of relating to two suicide attempts in his peer group. It is important to note, that firstly, when saving Trish he may be projectively identified with his therapist. And, secondly, whilst he shows greater concern for others ('I handled it in a mature way'), at that same time other members of the group are considering suicide. Suicidal behaviour has shifted within the group; firstly Eric and Sven made suicide attempts close in time to each other; later Trish and Kamina also made attempts (though the latter has not been discussed here). This suggests that the destructiveness of all group members becomes located in one person, through the projective identifications of the others, at a particular moment in time. It is an important speculative thought that the therapist's feelings of confusion and helplessness provide a hint of what might have been present in the minds of the group members, who were not able to bear these feelings but need to find ways of avoiding, and in other ways defending against the complications these feelings bring about that results in suicidal action. In this hypothesis, one person is loaded with group suicidal feelings and impulses leaving others free therefore to be more reasonable, ethical and responsible. This possibility is important because, if it is the case, it has serious implications for understanding these events, and for treatment interventions. If this is what was occurring -and we cannot be sure, but need to raise the possibility - the patient's freeing through 
projective identification of suicidal impulses might have, in particular circumstances such as these, the effect of putting other group members at risk.

Individual psychotherapy and the group processes

The therapist who is treating the suicidal individual is faced with many challenges, which increase when the patient reveals that others in a peer group are known to be suicidal or acting self-destructively. Concerns about confidentiality limit what the therapist may reveal to others, even those who may be in a position to intervene. There is an exception for when someone's life is in danger, but this becomes a gray area when the self-attack is reported some time after the occurrence or when the party involved is hard to identify. In this case it is important to emphasise that knowledge about the group emerged over time and had to be processed and responded to as and when new information arrived. Sometimes the veracity of the information is unclear; fantasy may be presented as true facts and important feelings and positions are split-off into different parts of a complicated system consisting of therapist, patient, group members and social organisations (e.g. the school). There are always contradictions and potential losses, including the potential loss of the therapeutic relationship, which therefore increases the risks for the identified patient, and, as the therapist has partial access to the unconscious processes in the group, to other group members. Sven himself pointed out the contradictions in these ethical dilemmas that are not easily resolved: when, forbidding the spread of information (Sven's first rule) he said: "In 
therapy everything is confidential unless someone is in danger. But that's the whole point of therapy, to talk about the most important things".

The therapist hearing this material is a faced with a new characterization of 'evenly hovering attention'. The primary object of the treatment is the patient in the room; in addition there are safety concerns for the other individuals at risk from self-attack; and thirdly, there is the therapist's own emotional reaction to the traumatic violence and experience of helplessness. This 'evenly hovering attention' is stressful and exhausting, and through its ambiguity can be confusing, and may lead to withdrawal or enactments. Discussion in supervision or in the therapist's own psychotherapy may help lead to clarity of therapeutic action.

\section{Limitations}

We have described a suicidal group from the vantage point of the individual psychotherapist. The limitation of this article is that evidence emerges from data obtained through one individual's treatment enlarged by discussions with teachers and the school councilor. We do not have direct access to the other students and families and therefore conclusions about their internal experiences are speculative. The group under discussion is a friendship group. However, the literature on point clusters suggests that connections between suicidal 
individuals can be less formed or evident than in this example. We suggest the dynamics discussed here may be applied more widely to other groups, especially perhaps groups that are more internet based; however further investigation is necessary to evaluate this possibility.

\section{Conclusion}

We describe a patient in psychotherapy following a suicide attempt who gradually reveals a group of at least four serious suicide attempts in his high school group. The destructiveness of the group relates to issues of containing or projecting internalized states of dysregulation. The clinical implications for treatment involve recognition of affective states_and inner relatedness that may be communicated between vulnerable individuals and the need for communication within systems, and with the broader treatment team. Further discussion and appreciation of the dynamics of projective identification in these groups can help the understanding of important aspects of group suicidal behaviour, including point clusters, orient therapists to the need to consider group factors within the individual treatment,_and play a role in suicide prevention. We have begun to chart the role of projective identification as a key explanation for the dynamics in group suicidal behavior. Whilst the information is restricted to the clinical material for one person, the approach appears to us to 
hold promise for the further study of suicidal groups of young people and also for further discussion of the difficulties - practical, technical and ethical - faced in this important aspect of psychotherapeutic work.

\section{References}

Anderson, R. (1999) Introduction, in Anastasopoulos, D., Laylou-Lignos, E. and Waddell, M. Psychoanalytic Psychotherapy of the Severely Disturbed Adolescent, London, Karnac Armstrong, D. (2005) Organization in the Mind: Psychoanalysis, Group Relations and Organizational Consultancy, London, Karnac Author (2008a) Author (2008b) Austin, A.E., van den Heuvel, C., \& Byard, R. W. (2011) J Forensic Sci. Nov; 56(6): 1528-30. doi: 10.1111/j.1556-4029.2011.01840.x. Epub 2011 Jul 25. 
Bandura, A. (1977). Self-efficacy: Toward a unifying theory of behavioral change. Psychological Review, 84, 191-215.

Berkowitz, L. (1984). Some effects of thoughts on anti- and pro-social influences of media effects. Psychological Bulletin, 95, 410-427.

Bell, D. (2008) Who is killing what or whom? Some notes on the internal phenomenology of suicide, in Briggs, S. Lemma, A., Crouch, W. (eds.) Relating to self-harm and suicide: psychoanalytic perspectives on theory, practice and prevention. London, Routledge

Bion, W. (1961). Experiences in groups and other Papers. London Tavistock/Routledge

Bion, W. (1962). Experiences in Groups. London, Maresfield Boyce, N. (2011). Suicide clusters: the undiscovered country. Lancet. Oct 22;378(9801):1452.

Chabrol, H. \&_Sztulman, H. (1997) Splitting And The Psychodynamics Of Adolescent And Young Adult Suicide Attempts, International Journal of Psychoanalysis, 78:1199-1208

Chotai, J. (2005). Suicide aggregation in relation to socio-demographic variables and the suicide method in a general population: Assortative susceptibility. Nordic Journal of Psychiatry, 59, 325-330. 
Clarke, S. (2001) Clarke, S. (2001) 'Projective Identification: From Attack to Empathy?' Journal of Kleinian Studies http://www.humannature.com/ksej/vol2.htm

Durkheim, E. (1951). Suicide. London, England: Routledge. (Original work published 1897).

Freud, A. (1936). The Ego and the Mechanisms of Defense: The Writings of Anna Freud, Vol 2: New York: Int Univ Press, 1966

Goethe, J. W. (1774). The Sorrows of Young Werther. (German: Die Leiden des jungen Werther). Classics Library Complete Collection, transl. Michael Hulse, Penguin Books, 1989, ISBN 0-14-044503-X

Haw C, Hawton K, Niedzwiedz C, Platt S (2013) Suicide clusters: a review of risk factors and mechanisms, Suicide Life Threat Behavior 2013 Feb; 43(1): 97108. doi: 10.1111/j.1943-278X.2012.00130.x.

Halton, W. (1994) Some unconscious aspects of organizational life; contributions from psychoanalysis, in Obholzer, A. \& Zagier Roberts, V. eds The Unconscious at Work, London, Routledge Johansson L, Lindqvist, P and Eriksson, A. (2006). Teenage suicide cluster formation and contagion: Implications for primary care. BMC Family Practice, 7,32 .

Joiner, TE. (1999). The clustering and contagion of suicide. Current Directions 
in Psychological Science, 8, 89-92.

Jones P., Gunnell, D., Platt, S., Scourfield, J., Lloyd, K., Huxley, P., John, A., Kamran, B., Wells, C., \& Dennis M. (2013). Identifying probable suicide clusters in wales using national mortality data. PLoS One. 2013 Aug 28;8(8):e71713. doi: 10.1371/journal.pone.0071713. eCollection 2013.

Klein, M. (1946). Notes on some schizoid mechanisms. Int J. Psycho-Anal., 27, 99-110 and in The Writings of Melanie Klein, London: Hogarth (1975).

Meltzer, D. (1984) Studies in Extended Metapsychology, Perthshire, Clunie Press

Sachs, M. \& Eth, S. (1981). Pathological identification as a cause of suicide on an inpatient unit. Hospital and Community Psychiatry, 32, 36-40.

Shapiro, E.R. (2009). A View From Riggs: Treatment Resistance and Patient Authority-XII. Examined Living: A Psychodynamic Treatment System. $J$. Amer. Acad. Psychoanal., 37:683-698.

Tainminen, T. (1992). Projective identification and suicide contagion. Acta Psychiatrica Scandinavica, 85, 449-452.

Waddell, M. (1998) Inside Lives: Psychoanalysis and the Growth of Personality, London, Karnac/Tavistock Clinic Series

Waddell, M. \& Williams, G. (1991) Reflections on Perverse States of Mind, Free Associations, 2, 22, 203-213 
Waska, R.T. (1999). Projective identification, self-disclosure, and the patient's view of the object: the need for flexibility. J Psychother Pract Res. J. Summer; $8(3): 225-33$.

Williams, G. (1997) Internal Landscapes and Foreign Bodies, London, Karnac Young, R. (1992) Benign and Virulent Projective Identification in Groups and Institutions, Human Nature, http://human-nature.com/rmyoung/papers/paper3h.html Zeneer, F. (2009) Suicide Clusters and Contagion Recognizing and addressing suicide contagion are essential to successful suicide postvention efforts. Principal Leadership, October 2009, 12-16, retrieved from http://www.nasponline.org/resources/principals/Suicide_Clusters_NASSP_Sept \%2009.pdf

\section{Acknowledgement}

We would like to thank the three anonymous reviewers for their comments on earlier versions of this article. 